\title{
ESTUDIO DE UNA LUCERNA ROMANA INÉDITA HALLADA EN Burriana (CASTEllón)
}

Burriana está situada en la costa de la provincia de Castellón, al S de la desembocadura del río Mijares, que sirve de límite de su término por el $\mathrm{N}$.

En época romana prolifera el poblamiento disperso de villae entre la costa y la Vía Augusta, donde destacamos la presencia de yacimientos (Sant Gregori, Palau, Regenta, El Palmeral) y asentamientos o embarcaderos costeros (Calamó, Torre d'Onda) (Arasa 1997).

La pieza objeto de este estudio fue recuperada por la arqueóloga Lidia Salvador durante el año 2007 en la excavación de urgencia llevada a cabo en el yacimiento de El Marjalet, situado a escasos metros de El Caminás, un importante eje viario paralelo a la costa que atraviesa longitudinalmente el término municipal. Este enclave corresponde a un gran vertedero donde se recuperaron abundantes materiales cerámicos, que aún permanecen inéditos. Es muy probable que El Marjalet esté relacionado con dos villas romanas muy cercanas: El Palau, que está situada a $3 \mathrm{~km}$ al O y está ocupada entre los ss. I y IV d.C., en la que se ha excavado parte de un complejo termal (Melchor y Benedito 2005); y con Sant Gregori, situada a unos 2,5 km hacia el E, actualmente se encuentra en proceso de excavación (Melchor et al. 2013).

\section{DESCRIPCIÓN}

Se trata de una lucerna de volutas, de la que encontraron el $90 \%$ de los fragmentos que componen la pieza, que se extrajo in situ por los servicios de restauración del Museo Arqueológico de Burriana. En el proceso de restauración, en el año 2008 se reconstruyó la parte que faltaba, el lateral derecho del orificio de luz y la zona de las volutas por simetría con el lateral izquierdo.

Esta lámpara lucernaria tiene una longitud completa de 11,4 cm. Cuenta con una sola prolongación del cuerpo (rostrum) y con un orificio para depositar la mecha (ellychnium) de 5,4 cm de ancho y 3,6 cm de largo, la anchura del rostrum es casi la misma cerca del depósito de aceite (infundibulum) que en las puntas de las volutas. La parte central de la lucerna, el discus, tiene 7,5 cm de diámetro, presenta una forma cóncava y va enmarcado por dos molduras sencillas en relieve (fig. 1).

La base de la pieza es plana y en ella se observa un círculo inciso en cuyo interior figura también incisa la inscripción P · A trazada a mano alzada mediante la utilización de un punzón antes de haber sido cocida la pieza. La letra P está realizada con mano firme y segura y la base de la letra está remarcada con una pequeña línea (fig. 3). 


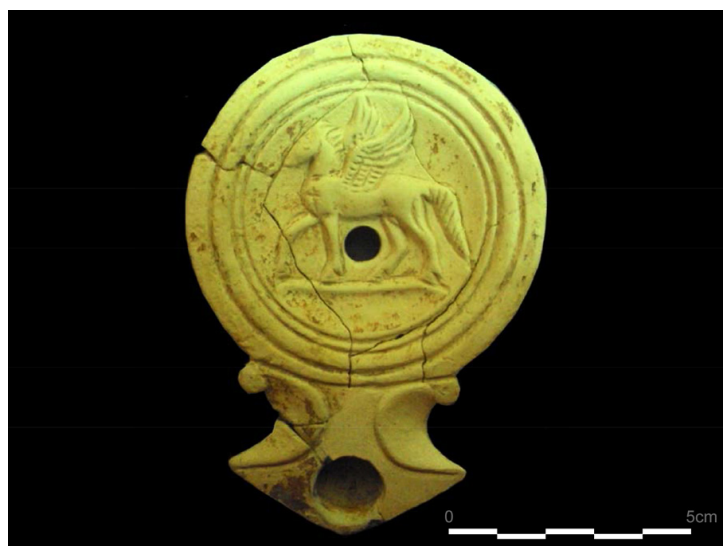

Fig. 1. Lucerna de El Marjalet.

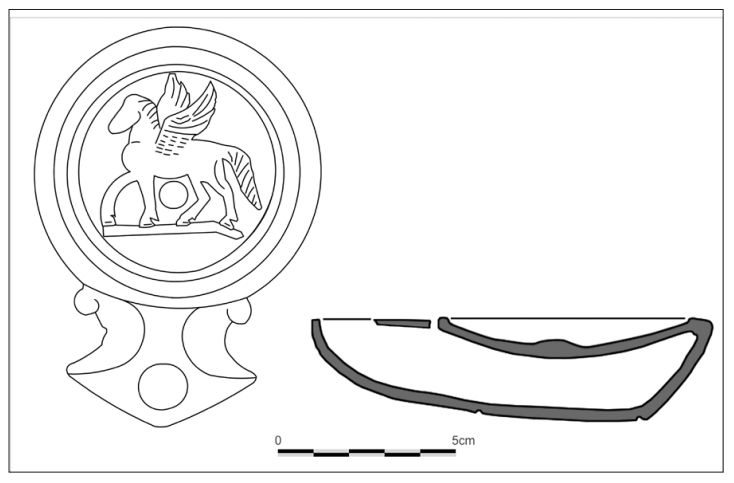

Fig. 2. Dibujo y perfil.

El motivo decorativo que se observa en la zona central de la cubierta de nuestra lucerna es la representación de Pegaso en posición de perfil, siendo su base una superficie horizontal, marchando pausadamente hacia el lado izquierdo con las alas desplegadas y terminadas en punta (fig. 1).

Es una pieza bien cocida y depurada, de buena factura y en muy buen estado de conservación. La pasta empleada en su fabricación es de una coloración amarillenta con tonalidades grisáceas y presenta indicios de haber estado recubierta con un engobe rojo.

\section{ESTUDIO}

Esta pieza es del tipo Loeschcke IC (1919), que se fecha en época Neroniana-Flavia, aunque su producción en las provincias tuvo un especial auge a partir de la etapa flavia (70-96 d.C.). Esta forma se corresponde con la

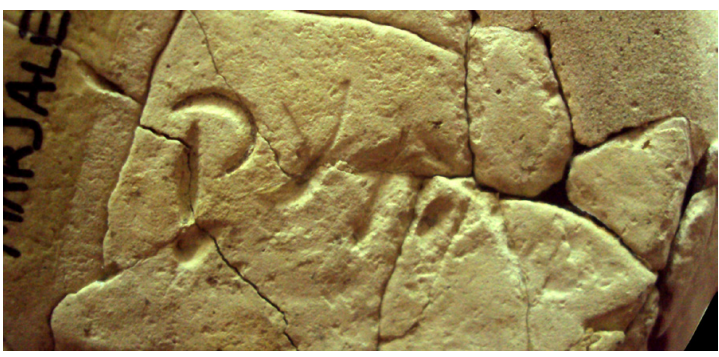

Fig. 3. Inscripción incisa.

de otros autores que la han catalogado con distintas nomenclaturas: Dressel 9C (1952), Walters 80, Bronner 22, Deneauve IVC (1969), Provoost IV2, 1,3, (1976), Leibund VII (1977), Bailey Av-vi (1980) entre otros, según datos facilitados por Beltrán (1990: 271) (fig. 2).

Este tipo de lucernas se caracteriza por tener el pico de forma triangular flanqueado a ambos lados por dos volutas en relieve y carecer de asa.

Las lucernas del tipo Loeschcke IC tuvieron un gran auge comercial, según demuestra su presencia en diversos lugares del Mediterráneo y del Centro de Europa, como puede verse en Pompeya, Herculano, Suiza, Hofheim (Morillo 1999: 79-81) y Francia (Bailey 1988: 189-191).

En la península Ibérica la forma Loeschcke la podemos encontrar en Cádiz (Quintero 1927), Andújar (Sotomayor et al. 1979), Sevilla (Fernández Chicarro 1956), Itálica (López Rodríguez 1981), Tarragona (Palanques 1992), Ampurias (Almagro 1955; Casas y Soler 2006), Bilbilis (Amaré 1988), Caesaraugusta (Amaré 1988) y necrópolis de Carmona (Bendala 1976) entre otros (Morillo 1999: 79-81).

Se conocen otros ejemplares de este tipo decorado con el mismo motivo que la de El Marjalet. Es el caso de dos lucernas que se encuentran depositadas en el Museo Británico. La primera de ellas se fecha en el 90-150 d.C. Está cubierta con un engobe de color naranja-marrón y tiene la imagen de Pegaso en el disco, la parte posterior y gran parte de la cara inferior están desaparecidas, por lo que no se puede saber si portaba algún tipo de inscripción. La segunda fue hallada en Petra y se fecha en el 30-70 d.C., presenta la misma decoración y en la base una inscripción con la letra I (Bailey 1980: 215; 1988: 278).

Por otro lado, en el Museo de Sevilla se conservan dos lucernas con características similares. Una de ellas (REP 6690), de procedencia desconocida, muestra la imagen del caballo alado caminando hacia la izquierda con la pata alzada. La otra (REP 1984/455), hallada en 
Dos Hermanas (Sevilla), también presenta la imagen en relieve del Pegaso. Ambas piezas están fragmentadas y no conservan la parte inferior, por lo que no se puede saber si tenían algún tipo de inscripción.

Existen también paralelos de esta imagen en otros lugares como Mérida, Itálica, Museo de Gerona, Aragón, Conimbriga, Cartago (Morillo 1999: 195-196).

Respecto a la inscripción incisa en la base de nuestra pieza, contamos con algunos paralelos. Uno de ellos procede de Tipasa (Argelia) en la tumba B-4 de una necrópolis, donde se halló una lámpara lucernaria de volutas con asa, en cuya base en parte quebrada figura la marca incisa P.A. La forma es similar a la nuestra, pero no presenta la misma imagen en la parte superior, pues aquí se muestra el busto de un hombre con pelo lanudo coronado por una media luna (Bussière 2000: 263).

Otro ejemplo se encuentra en el emplazamiento romano de Tamuda, situado a $5 \mathrm{~km}$ de Tetúan (Marruecos), de donde procede una lucerna votiva de pasta rosácea sin barniz, de boquilla simple y voluminosa con abertura grande y con trazas de calcinamiento en cuya base figura igualmente la inscripción P.A. (Bussière 2000: 269).

Esta marca incisa no se ha podido poner en relación con algún nombre o taller debido a que se han hallado pocos paralelos y en contextos geográficos distantes. Ambas letras están separadas por un punto y podrían corresponder a las iniciales de un nombre.

Conocemos una lucerna del mismo tipo que la que aquí se describe y en cuya base figura incisa la letra $\mathrm{P}$ (Astorga, colección particular) (Morillo 1999: 301). Algunos autores como Bailey proponen la identificación de esta letra con el taller de Paccius (Bailey 1980 III: 99).

\section{CONCLUSIONES}

Según la información consultada y el estudio de los datos se puede fechar la pieza en época Neroniana-Flavia, siendo la mayor producción de este tipo en la etapa flavia (70-96 d.C.). En lo referente a la decoración y considerando las investigaciones hechas por A. Morillo (1999) sobre las lucernas de la Península Ibérica, se puede afirmar que la representación de Pegaso fue empleada a lo largo del s. I d.C.

Respecto a la interpretación de la abreviatura P·A, no podemos atribuirla a un nombre de autor o taller en concreto, ya que no hay suficientes datos, por el momento, que permitan relacionar las iniciales con una denominación específica.

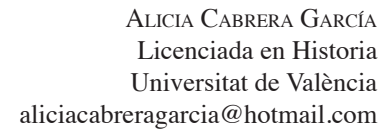

\section{AGRADECIMIENTOS}

Queremos agradecer a la arqueóloga Lidia Salvador y al director del Museo de Burriana José Manuel Melchor, las facilidades para estudiar esta pieza.

\section{BIBLIOGRAFÍA}

ALMAGRO, M. (1955): Las necrópolis de Ampurias II, Barcelona. AMARÉ, M. T. (1988): Lucernas romanas de Aragón, Instituto Fernando el Católico. Zaragoza.

ARASA, F. (1997): L’Època romana, XXX Aniversari del Museo Arqueològic Comarcal de la Plana Baixa, Burriana.

BAILEY, D. M. (1980): A catalogue of the lamps in the British Museum II: Roman provincial lamps, London.

BAILEY, D. M. (1988): A catalogue of the lamps in the British Museum III: Roman lamps made in Italy, London.

BELTRÁN, M. (1990): Guía de la cerámica romana, Zaragoza.

BENDALA, M. (1976): La necrópolis romana de Carmona, 2 vols., Sevilla.

BUSSIÈRE, J. (2000): Lampes antiques d'Algérie, Montagnac.

CASAS, J.; SOLER, V. (2006): Lucernas romanas en el extremo nordeste de la Península Ibérica, BAR-IS, Oxford.

FERNÁNDEZ CHICARRO, C. (1956): La colección de lucernas antiguas del Museo Arqueológico de Sevilla, Memorias de los Museos Arqueológicos Provinciales XIII-XIV, Madrid.

LÓPEZ RODRÍGUEZ, J. R. (1981): La colección de lucernas de la casa de la condesa de Lebrija (Sevilla), Valladolid.

MELCHOR, J. M.; BENEDITO, J. (2005): Segunda campaña de intervenciones arqueológicas en el edificio termal romano del Palau (Burriana-Castellón), XXXII Congreso Nacional de Arqueología, Bolskan 20, 237-242.

MELCHOR, J. M.; BENEDITO, J.; FERRER, J. J. (2013): La villa romana de Sant Gregori, Preactas del XVIII Congreso Internacional de Arqueología Clásica, Mérida, 176.

MORILLO, A. (1999): Lucernas romanas en la región septentrional de la península Ibérica, Montagnac.

PALANQUES, M. L. (1992): Las lucernas de Pollentia, Palma de Mallorca.

QUINTERO, P. (1927): Excavaciones en Cádiz. Memoria de las excavaciones practicadas en 1927, Junta Superior de excavaciones y Antigüedades, Madrid.

SOTOMAYOR, M.; ROCA, M.; SOTOMAYOR, A. (1979): Los alfares romanos de Andújar. Campañas de 1974, 1975 y 1977, NAH 6, 443-497. 